\title{
In-depth learning and development of experimental and team work skills in laboratory courses
}

\author{
Clémence Fauteux-Lefebvre, Denis Gravelle, and Nicolas Abatzoglou(*) \\ Université de Sherbrooke, Department of Chemical \& Biotechnological Engineering \\ (*) Corresponding author: Nicolas.Abatzoglou@USherbrooke.ca
}

\begin{abstract}
Laboratory courses help students understand the application of theoretical principles and develop their synthesis abilities and critical thinking. Although the above target is well understood in our profession and has long been integrated to the Chemical Engineering curriculum, there are various ways to reach these objectives and it is still a matter of intense discussion.

This work presents a laboratory course at the Department of Chemical \& Biotechnological Engineering of the Université de Sherbrooke. This course basically seeks to provide the students with elements allowing them to link fundamental knowledge in thermodynamics, transport phenomena and physical chemistry/kinetics to experimental results. However, for engineers, this must be positioned within a context which is the closest possible to their everyday professional reality which requires crosscurricular competencies and attributes. The latter includes team work, project management, and of course fast and efficient analytical, synthesis and interpretation skills. The laboratory course presented here is given in the middle of the program leading to the engineering bachelor's degree.

All experimental design, data collection, laboratory manipulations and analyses are performed by teams of students. There are 11 labs and every team goes through all of them. To develop their project management skills, our Department has adopted the formula of the "Master Team". The class is divided in a number of teams equal to the number of experiments. Each team is named responsible (Master team) of one of the experiments for the entire semester. In this role, it supervises the reporting of all other teams and proceeds to the final (global) report and its oral presentation.

The success of this organization depends on the competence of the teaching team as well as the efficient internal management of each Master team. Thus, the teams develop skills which lead them to the final and most difficult part of their Chemical Engineering education, the Capstone Design course.
\end{abstract}

\section{Introduction}

Laboratory courses are part of chemical engineering curriculums worldwide. The tasks of the future engineer make the laboratory courses a necessity. They are the most important components of any active learning process and they have several advantages. As reported in [1], active learning involves the learner in the active processing of learning, and helps him/her better realize what is well understood and what is missing. Consequently, this process has a considerable positive impact on motivation since learners perform tasks whose usefulness is evident to them and they are at least partially responsible of their own education.

In [2], the authors present their approach in the first thermodynamic course of an engineering degree. They give laboratories along with the required theoretical elements. They found that the approach of combining laboratories with classrooms learning techniques (combination of exercises and experiences) reinforce procedure and generalization.

In [1], the authors report the advantages of team learning. In addition to gaining skills in cooperative working, which is essential for many professions, working in team is an opportunity for mutual support and motivation as well as an opportunity to elaborate (i.e. to put the subject matter into their own words) and use the language of the discipline. Therefore team work in laboratory courses offers many advantages to students.

The topic of this work is the physico-chemical laboratory course. This course is entirely based on laboratory work without any type of parallel theoretical teaching. The theoretical background required is taught in the prerequisite courses.

1.1 Course Positioning in the Université de Sherbrooke Chemical Engineering Curriculum

The chemical engineering undergraduate program taught at Université de Sherbrooke is a cooperative program; it combines courses and training terms 
(semesters of 4 months each) in which the students work as remunerated interns in industry and various other places. The program is composed of 8 course terms taking place at the University and 5 internship semesters at the work place. As shown in table 1, the course Physico-chemical laboratories presented in this work is given in course semester 5 .

Table 1 Position of the Physico-chemical laboratories courses in the curriculum

\begin{tabular}{|c|c|c|c|}
\hline Term & \multicolumn{3}{|c|}{ Courses } \\
\hline S1 (Fall) & $\begin{array}{l}\text { GCH } 111 \\
\text { Organic } \\
\text { chemistry }\end{array}$ & $\begin{array}{l}\text { GCH } 101 \\
\text { Introduction } \\
\text { to chemical } \\
\text { engineering }\end{array}$ & \\
\hline $\begin{array}{l}\text { S2 } \\
\text { (Winter) }\end{array}$ & $\begin{array}{l}\text { GCH } 120 \\
\text { Analytical } \\
\text { techniques }\end{array}$ & $\begin{array}{l}\text { GCH } 201 \\
\text { Chemical } \\
\text { energetics }\end{array}$ & $\begin{array}{l}\text { GCH } 112 \\
\text { Inorganic } \\
\text { chemistry }\end{array}$ \\
\hline $\begin{array}{l}\text { T1 } \\
\text { (Summer) }\end{array}$ & \multicolumn{3}{|c|}{ Co-op Work Term 1} \\
\hline S3 (Fall) & & $\begin{array}{l}\text { GCH } 301 \\
\text { System } \\
\text { energetics } \\
\text { analysis }\end{array}$ & \\
\hline $\begin{array}{l}\text { T2 } \\
\text { (Winter) }\end{array}$ & \multicolumn{3}{|c|}{ Co-op Work Term 2} \\
\hline $\begin{array}{l}\text { S4 } \\
\text { (Summer) }\end{array}$ & & $\begin{array}{l}\text { GCH } 321 \\
\text { Reaction } \\
\text { systems }\end{array}$ & \\
\hline T3 (Fall) & \multicolumn{3}{|c|}{ Co-op Work Term 3} \\
\hline $\begin{array}{l}\text { S5 } \\
\text { (Winter) }\end{array}$ & & $\begin{array}{l}\text { GCH } 330 \\
\text { Physico- } \\
\text { chemical } \\
\text { laboratories }\end{array}$ & \\
\hline
\end{tabular}

The courses presented in Table 1 are those directly related to the subjects covered by the Physicochemical laboratory course. The objective of the course is to master the fundamental elements and kinetics in chemical engineering unit operations through hands-on practice using lab-scale experimental set-ups.

There are two main differences between this and a traditional laboratory course. First, it is not given in conjunction with a traditional theoretical course but just after having taught classical thermodynamics. The second and most valuable difference is the level of autonomy the students are given at almost all steps of the learning procedure. As explained in the methodology section, the class is divided in a number of teams and each team is responsible of one laboratory. Each team receives an information package for each laboratory containing all the necessary components concerning the experiment. This package is not directive but rather informative; meaning that it teaches the team what they will see in this laboratory without telling them how they will do so. Thus, each team decides the specific experimentations to be performed, under the supervision of the team which is nominated upstream "Laboratory Master Team" and which constitutes the coaching team for this specific laboratory.

\section{Methodology}

\subsection{Course logistics}

The notion of Master Team is central in the logistics of this course and constitutes the major innovation presented here. In the next we will call this procedure the "Master Team format". In this format, each team is responsible of one of the 11 laboratories for the entire term. At the beginning of the session, each Master Team plans all the experiments (conditions and type) to be done in order to gather sufficient information to analyse the phenomena as thoroughly as possible. Then, every week each Master Team, explains the laboratory to the other teams (called from now on "operating "teams"), gives the necessary indications/instructions and make sure that the experiments are properly carried out. Then, at the end of each experimental run, each Master team collects the data generated by all teams to perform an in-depth analysis of their experiment.

Every week, the team working on a specific laboratory unit performs a short analysis of the collected data. In summary, every team of students is simultaneously a Master team for one of the laboratories and an operating team for the ten other laboratories. A schematic representation of the different roles for a team is shown in Figure 1. It can be seen that team one is the Master team for the laboratory 1 and an operating team for the laboratory 2. Table 2 presents the schedule of the semester.

Figure 1: Schematic representation of the different roles of the students teams

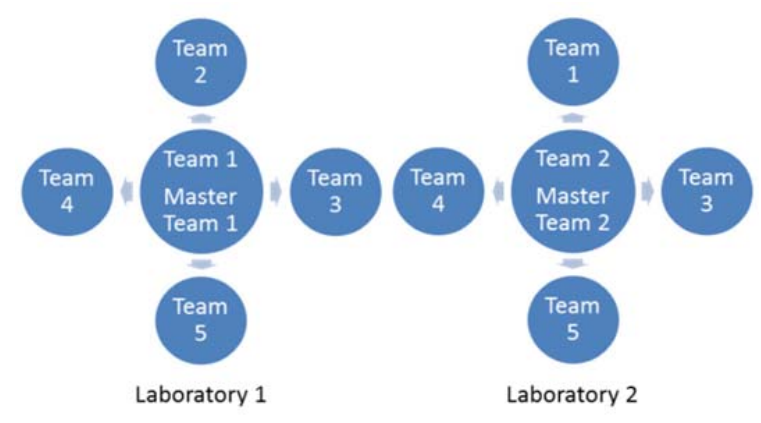


Table 2 : Schedule of the semester

\begin{tabular}{|l|l|}
\hline Weeks in the semester & \multicolumn{1}{|c|}{ Students' tasks } \\
\hline Week 1 & $\begin{array}{l}\text { Presentation of the } \\
\text { course/ Master teams } \\
\text { learn about their } \\
\text { experimental set-up }\end{array}$ \\
\hline Week 2 & $\begin{array}{l}\text { Master terms continue } \\
\text { learning and finalise } \\
\text { planning for the semester }\end{array}$ \\
\hline Week 3 to Week 12 & $\begin{array}{l}\text { Master teams become } \\
\text { operating teams and } \\
\text { realise the experiment as } \\
\text { decided by the Master } \\
\text { teams; one laboratory per } \\
\text { week }\end{array}$ \\
\hline Week 13 & $\begin{array}{l}\text { Analysis of the collected } \\
\text { data and presentation to } \\
\text { the rest of the class by } \\
\text { Master teams. }\end{array}$ \\
\hline
\end{tabular}

\subsection{Laboratories}

There are 11 different laboratories related to thermodynamics and Chemical Reaction Engineering. They are listed below along with their main objectives:

1) Heat effect - Constant Pressure: Determine the enthalpy of fusion of pure solvent (melting point of solution) and heat of reaction (acid-base).

2) Heat effect - Constant Volume: Determine the heat of combustion.

3) Viscosity: Measure and compare viscosity of Newtonian fluids as a function of temperature and viscosity of non-Newtonian fluids.

4) Conductivity: Measure and compare heat transfer coefficients for forced and natural convection with different fluids.

5) Diffusivity: Evaluate the molar flux and the concentration profile of a solvent in a gas.

6) Fugacity: Measure and calculate compressibility factor and fugacity of gases experimentally and through mathematical correlations.

7) Energy balance: Realise energy/exergy balance on a real system and study the effect of parameters on heat transfer during the heating of a liquid.

8) Phase equilibrium: Measure and evaluate the properties of pure liquid and liquid mixture in equilibrium and determine equilibrium constants for a two-phase liquid mixture.

9) Combustion: Do mass and energy balances and determine efficiency and energetic yield.

10) Batch and Continuous stirred tank reactors (CSTR): Evaluate the kinetic rate constant and the
Arrhenius equation (the activation energy and the preexponential factor) and characterise CSTRs in series.

11) Packed bed reactor (PBR): Mass and energy balance and study of a thermo-catalytic reaction.

The common objective in all labs is to understand and explain the theoretical principles and mechanisms involved as well as to understand the importance of the experimental conditions. In addition, Master teams have the mandate to perform an extensive analysis of the entire set of data obtained in the semester.

\section{Examples}

Two examples of the work accomplished by a Master team are presented below.

The first laboratory presented here concerns the determination of physical properties. It requires integration of knowledge from Thermodynamics courses in the previous terms: the term "horizontal integration of knowledge" is used to describe this process. The second laboratory is about chemical reaction with vertical integration of knowledge, since students are required to integrate knowledge from courses covering different topics (reaction systems and energetics).

\subsection{Fugacity and Compressibility}

In this laboratory each operating team measures and calculates the compressibility factor and the fugacity of either carbon dioxide or nitrogen, at different temperatures using a Burnett cell. Each team runs the experimental part at one predefined set of conditions (one gas at one temperature). In addition to comparing the results obtained by the operating team with the different correlations found in the literature, the Master team calculates the enthalpy of the gases using residual properties.

Since, in the case of pure gas, the residual property is the difference between the property for the ideal gas and the property of a real gas, the enthalpy for a pure gas is determined using Equation (1). To evaluate the residual enthalpy, Equation (2) is used. Equation (3) gives the relation between fugacity and Gibbs energy. Since the operating teams measure the fugacity at different temperatures, the Master team can use the data to evaluate the residual enthalpy and therefore the enthalpy of the gas. In addition, they can use Equation (4) to evaluate the residual entropy. The equations are taken from [3] and it should be noted that the only the main equations and calculation steps are shown. 


$$
\begin{gathered}
H=H_{0}+\int_{T_{0}}^{T} C_{p} d T+H^{R} \\
H^{R}=-R T^{2}\left[\frac{\partial\left(G^{R} / R T\right)}{\partial T}\right]_{P} \\
G^{R}=R T \ln \phi \\
S^{R}=\frac{H^{R}-G^{R}}{T}
\end{gathered}
$$

\subsection{Reaction in a Packed Bed Reactor}

For this laboratory, each operating team has the mandate to perform a parametrical study of catalytic oxidation of propane using a platinum-based catalyst. A set of operating conditions with different flow rates, inlet temperatures and ratios of oxygen/propane are tested. Every operating team calculates mass balance and energy balances and, therefore, is able to evaluate the enthalpy of reaction and conversion (reaction extent).

The master team of this laboratory has two objectives for their analysis of the data collected throughout the semester: First, to analyse the stability of the catalyst efficiency, by evaluating if there is a decrease in conversion after ten experimental runs; Second, to calculate the variation of entropy in the system.

From these two examples, it can be seen that the students of each team enrich their knowledge from each laboratory because, as the operating team, they conduct the experiments, perform the calculations and analyse the results.

Finally, being responsible of a laboratory as a Master team gives them the opportunity of doing an in-depth analysis either by having data that cannot be collected in a single experiment (each laboratory session is 4 hours) or by comparing different sets of data or variations of data over time.

\section{Discussion and Conclusion}

\subsection{Student's Learning}

It is demonstrated that the format of this laboratory course help students to improve their theoretical knowledge in thermodynamics/chemical energetic. In comparison with a laboratory course given in parallel with the theoretical course, this course gives the student the opportunity to revisit the different subjects a few months after the last "classroom" course in this part of the discipline.

Moreover, it helps students develop skills in experimental planning and data analysis in a period of three months. They have to schedule and organise the entire set of experiments for one semester.

Students also improve their teamwork skills. First, they have to work in teams to plan the experiments, the analysis of their data and also for the laboratories they do as operating team, for which they have to submit a weekly team report. Second, they have to work in collaboration with the other teams, since each week a different team performs the experiment for which they are named master team. Therefore, they have to make sure that they give sufficient and correct information to the operating team and they are well organised to collect the data. They also have to insure that the calculations and manipulations are well understood by the operating team.

This course is given in the middle of our Chemical Engineering curriculum. It is not the first contact the students have with experimental planning, analysis and team work, since they have an integration project in their first year of study in which they work on a project for two semesters, also within the framework of a relatively large team of student (4-8). The $1^{\text {st }}$ year project course, this laboratory course as well as another on unit operations all contribute to prepare all the students for the capstone design course at the end of their curriculum and finally it prepares them to enter the engineering profession.

\subsection{Problem Encountered and Solutions}

As mentioned in the previous section, one of the skills developed in this course is team working. However, some problems are also encountered; they mainly concern the transmission of information, planning of the work, separation of the tasks and organisation of efficient team meetings.

There is no formal teaching on team work, but the teaching team helps groups that could have difficulties especially with planning and transmission of information. Team work is not directly assessed in the course, but teams of students that work more efficiently together are usually more adept at performing the required tasks..

\subsection{Teaching Team's Learning}

Since the students are really involved in their laboratory course, they feel very concerned and they 
have new suggestions each year. For example, they propose new measurements that could improve the analysis of the phenomena and they think about additional calculations to perform if more data were available. Therefore, the laboratories are continuously being improved.

Concerning the team work, since every group of students has particularities, the teaching team tries to develop new tools to help students in performing better and learn more efficiently.

\subsection{Future Improvements}

One of the main objectives of this course is to ensure that every student receives efficiently all the expected learning. In this course a large part of the work is done in teams. Thus, there is a final individual examination in order to evaluate each student separately.

However, to make sure that every student learns as much as possible from each laboratory experiment, the teaching team is actually examining the possibility to add a step prior to the experiment, aimed at a most efficient theoretical preparation of the laboratory by each team.

\section{Acknowledgements}

The authors would like to thank the technicians of the course which are part of the teaching team and the students that were taking the courses. Special thanks to Prof. Ryan Gosselin for reviewing this manuscript.

\section{References}

[1]M. Svinicki and W.J. McKeachie, McKeachie's Teaching Tips - Stategies, Research and Theory for College and University Teachers, Houghton Mifflin, Boston, 2011.

[]J.P. O’Connell and T.C. Scott, "Workshop exercices for connecting fundamentals to equipment in the first thermodynamics course", ASEE Annual Conference Proceedings, 2000, pp. 6929-6938.

[3]J.M. Smith, H.C. Van Hess, and M.M. Abbott, Introduction to chemical engineering thermodynamics, McGraw-Hill, United States, 2004.

\section{Nomenclature}

$C_{p}$ : Specific heat capacity

$G^{R}$ : Residual Gibbs energy
$H$ : Enthalpy

$H_{0}$ : Enthalpy of the ideal gas at reference temperature

$H^{R}$ : Residual enthalpy

$R$ : Ideal gas constant

$S^{R}$ : Residual Gibbs energy

$T$ : Temperature

$T_{0}$ : Reference temperature

$\Phi$ : Fugacity 